\title{
Prevalence of different forms of neuropathies in type 2 diabetes patients attending a tertiary care hospital in Central Gujarat: A hospital based cross sectional study
}

\author{
Balaji W. Ghugare ${ }^{1}$, Mukesh R. Dinkar2,", Himanshu Chauhan ${ }^{3}$ \\ ${ }^{1}$ Assistant Professor, ${ }^{2}$ Professor \& HOD, ${ }^{3}$ Tutor, Dept. of Physiology, GMERS Medical College, Gotri, Vadodara, Gujarat, India \\ *Corresponding Author: \\ Email: mukeshdinkar69@gmail.com
}

Received: $08^{\text {th }}$ September, 2017

Accepted: $02^{\text {nd }}$ February, 2018

\begin{abstract}
Introduction: Diabetic neuropathy (DN) is commonest forms of complications observed in type 2 diabetes patients. Due to variations in clinical and electrophysiological diagnostic criteria for polyneuropathies, prevalence of diabetic neuropathy varies in different studies. We used only (Electro diagnostic) EDX criteria for diagnosis of neuropathies in present study.

Aim and Objectives: To estimate prevalence of diabetic neuropathy; viz, mononeuropathy, polyneuropathy and mononeuropathy with coexistent polyneuropathy in population of subjects with type 2 diabetes mellitus.

Materials and Methods: It was a cross sectional study where total 53 diabetic subjects (30 male, 23 female) in age range 30-60 years were electrophysiologically evaluated for neuropathies during January 2013 to December 2015. Routine and specialized Nerve conduction studies were adopted for evaluation. Data was acquired and stored in Microsoft excel and analyzed using graph pad prism software.

Results: Overall prevalence of diabetic neuropathy (DN) was $54.71 \%$. Prevalence of other forms viz. Polyneuropathy only, mononeuropathy only and mononeuropathy with coexistent polyneuropathy are $30.18 \%, 16.98 \%$ and $7.54 \%$ respectively. Median neuropathy at wrist was the only form of mononeuropathy observed in these cases. Severity of mononeuropathy was observed more in diabetes without polyneuropathy cases.

Conclusion: Prevalence of different forms of neuropathies observed in present study is similar to previous studies. We observed more severe mononeuropathy in diabetes without polyneuropathy cases. Palm wrist comparison study must be part EDX evaluation in these cases.
\end{abstract}

Keywords: Diabetes mellitus, Diabetic polyneuropathy, Nerve conduction study.

\section{Introduction}

Diabetic neuropathy (DN) is one of the commonest forms of complications observed in diabetic patients. ${ }^{1}$ In a prospective study by Pirart $\mathrm{J}$ et al, incidence of diabetic neuropathy was more than $50 \%$ after 25 years of diagnosis. ${ }^{2}$ In a cross-sectional multicenter study of 6,487 diabetic patients in the U.K., the prevalence of DN increased with age and reached $44.2 \%$ in individuals between 70 and 79 years of age. ${ }^{3} \mathrm{DN}$ is often insidious in onset and may result in sensory loss, predisposing to callus formation that can fissure, become infected, and may precipitate plantar ulceration. ${ }^{4} \mathrm{DN}$ is significantly associated with morbidity including recurrent foot ulcers, infection and its amputation. Early diagnosis of DN can decrease patient morbidity by allowing for potential therapeutic interventions, including patient education and regular foot surveillance. However, there is no single diagnostic test for the detection of DN. ${ }^{5}$

Thus, variations in the prevalence of $\mathrm{DN}$ have been attributed to variation in age group of subjects, age of diabetes, glycaemic control, and most importantly the different criteria used to form its diagnosis. Some studies adopted only clinical and neurological examination whereas others have used clinical neurological examination plus electrodiagnostic studies (EDX). Among EDX criteria also, few studies included autonomic neuropathy (AN) along with abnormalities in two or more nerves. Few studies also included mononeuropathies like median, ulnar or peroneal neuropathies that are often reported in diabetic patients. With above background present study is aimed at estimating prevalence of various forms of neuropathies like mononeuropathy, polyneuropathy, mononeuropathy with coexistent polyneuropathy in diabetic population in a rural teaching hospital in central India.

\section{Materials and Methods}

It was a Cross sectional study conducted during January 2013 to December 2015 in Neurophysiology Laboratory in the department of Physiology.

Selection of cases: Cases were selected from patient attending Medicine OPD, with supportive inclusion and exclusion criteria under supervision of Consultant Physician. Inclusion criteria consisted of diabetic patients with age ranging from 30 to 60 years. It included type II diabetic patients diagnosed by physician after appropriate clinical and minimum supportive laboratory investigation with or without clinical evidence of mono or polyneuropathy. We excluded patients with age group less than 30 and more than 60 years, with obesity, pregnancy and alcoholism. We also excluded patients with systemic illness like hypothyroidism, tuberculosis, 
and trauma. Vascular diseases, neuromuscular disorders, treated cases of Carpel tunnel syndrome patients were also excluded from study. Patients were informed about the study and a written consent was taken thereafter. Approval from institutional ethics board was taken.

Electrodiagnostic study (EDX): After screening, patients underwent EDX that comprised of median and ulnar motor and sensory conductions, median and ulnar F wave study bilaterally. Standard techniques were followed to perform the EDX. Belly tendon montage was used for placement of recording electrodes in case of motor study and supramaximal stimulated to obtain CMAPs (compound muscle action potential). Antidromic sensory conductions were done for median and ulnar nerves. F wave were obtained in same motor study settings and ten records were obtained for analysis. A palm-wrist mixed comparison study was also done to explore median neuropathy at wrist.

Electrodiagnosis of Neuropathy: "Diabetic Polyneuropathy (DPN)" was diagnosed if the sensory and / or motor nerve conduction studies were abnormal for both median and ulnar nerves with a normal palmwrist comparison tests. "Median or ulnar mononeuropathy with coexistent polyneuropathy" was diagnosed if palm-wrist comparison study revealed latency difference $>0.4 \mathrm{~ms}$ along with median and ulnar motor and/or sensory nerve conduction study (NCS) abnormalities. "Diabetic mononeuropathy (DMN)" was diagnosed if only palm-wrist comparison was abnormal with normal routine conductions. For all technical and electrodiagnostic criteria we referred normative values from DC Preston and BE Shapiro's book "electromyography and neuromuscular disorders". ${ }^{6}$

\section{Statistical Analysis}

Analysis was done using Graph Pad prism software designed by GraphPad software Inc California USA under the guidance of statistician.

\section{Results}

Table 1 shows distribution of diabetic population. Study comprises of total 53 patients (30 male and 23 female) in the age range 31 to 60 with mean age 51.52 and SD 7.68. 65\% patients were in the age range 51-60 years whereas remaining $35 \%$ were in the age range 31 50 years.

Table 1: Age and Gender wise distribution of Participants

\begin{tabular}{|c|c|c|c|}
\hline \multirow{2}{*}{ Age in years } & \multicolumn{2}{|c|}{ Gender } & \multirow{2}{*}{$\begin{array}{c}\text { Total number } \\
\text { of subjects }\end{array}$} \\
\hline & Male & Female & \\
\hline $31-40$ & $5(16.66)$ & $3(13.04)$ & $8(15.10)$ \\
\hline $41-50$ & $4(13.33)$ & $7(30.43)$ & $11(20.75)$ \\
\hline $51-60$ & $21(70.00)$ & $13(56.52)$ & $34(64.15)$ \\
\hline Total & $30(56.60)$ & $23(43.40)$ & $53(100)$ \\
\hline Mean \pm SD & \multicolumn{3}{|c|}{$51.52 \pm 7.68$} \\
\hline
\end{tabular}

(Note: values in parenthesis indicate percentage, $\mathrm{SD}=$ standard deviation)

Fig. 1 shows distribution of various neuropathies in diabetic population. Out of 53 patients $29(54.71 \%)$ had one or other form of neuropathy. 9 patients $(16.98 \%)$ had purely median mononeuropathy at wrist. Other mononeuropathy in upper limb like ulnar neuropathy at wrist or elbow or radial neuropathy at spiral groove were not seen. Purely diabetic polyneuropathy without any evidence of ulnar or median mononeuropathy was observed in 16 out of 53 patients $(30.18 \%)$ and diabetic mononeuropathy with coexistent polyneuropathy was observed in 4 patients $(7.54 \%)$.

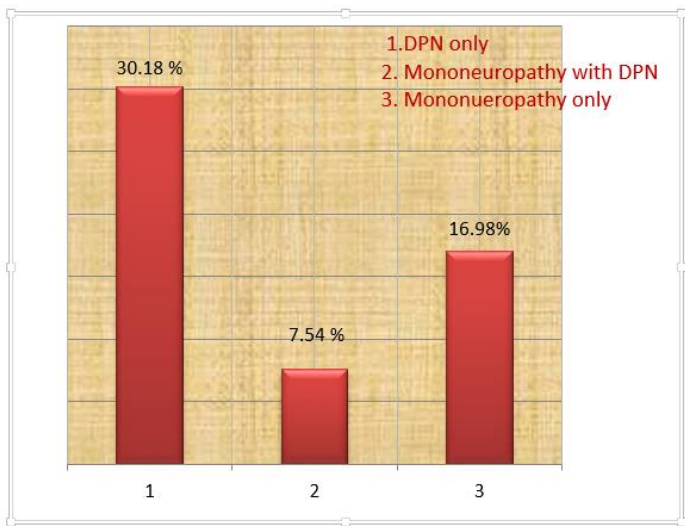

(Note: DPN= diabetic polyneuropathy)

Fig. 1: Prevalence of DPN only, DPN with coexistent mononeuropathy and Mononeuropathy only in study population

Table 2 Shows distribution of mild, mild to moderate, moderate and severe forms of mononeuropathy in diabetic population with and without polyneuropathy. Standard Criteria to classify severity of 
different forms of mononeuropathy were used from Shapiro et al. ${ }^{6}$

1. Mild: Median Vs. Ulnar latency difference $>0.4 \mathrm{~ms}$ with normal routine conductions,

2. Mild to moderate: Prolonged sensory and motor latencies of median nerve,

3. Moderate: prolonged latencies, reduced amplitudes and CV (conduction velocities),

4. Severe: severely reduced or absent amplitude and CV.

Table 2 shows that mild median mononeuropathy was common among diabetic without polyneuropathy and severe median mononeuropathy was common among diabetic with polyneuropathy.

Table 2: Severity of mononeuropathy in Diabetic population with or without polyneuropathy

\begin{tabular}{|l|c|c|}
\hline Prevalence & $\begin{array}{c}\text { Diabetic with } \\
\text { PN (n=20) }\end{array}$ & $\begin{array}{c}\text { Diabetic without } \\
\text { PN }(\mathbf{n = 3 3 )}\end{array}$ \\
\hline Mild & $1(5)$ & $5(15.15)$ \\
\hline $\begin{array}{l}\text { Mild to } \\
\text { Moderate }\end{array}$ & $1(5)$ & $1(3.03)$ \\
\hline Moderate & $0(0)$ & $2(6.06)$ \\
\hline Severe & $2(10)$ & $1(3.03)$ \\
\hline Total & $4(20)$ & $9(27.27)$ \\
\hline
\end{tabular}

(Note: Values in parenthesis indicate percentage, $\mathrm{PN}=$ Polyneuropathy)

\section{Discussion}

In present study, we observed that out of 53 diabetic subjects studied, 16 (30.18\%) were found to have only polyneuropathy, $4 \quad(7.54 \%)$ were having mononeuropathy with coexistent polyneuropathy and only mononeuropathy was observed in 9 (16.98\%) subjects. This suggests that mononeuropathy may or may not be associated with polyneuropathy in these subjects; rather it is more prevalent alone among these subjects.

Our observation is in accordance with findings by Perkins BA et al who observed $30 \%$ prevalence of Carpel tunnel syndrome (CTS) in diabetic subjects with polyneuropathy. ${ }^{7}$ Similar was the observation by Solomon D et al, Chammas $\mathrm{M}$ et al.$^{8,9} \mathrm{Comi} \mathrm{G}$ et al found prevalence of diabetic polyneuropathy as $41.8 \% .^{10}$ Stamboulis E et al found that CTS being correlated with diabetic polyneuropathy. ${ }^{11}$ Thomas P K et al reported 5$60 \%$ prevalence of diabetic polyneuropathy. ${ }^{12}$ Chammas $\mathrm{M}$ et al and Gamstedt $\mathrm{A}$ et al documented prevalence of CTS in diabetes being $15-25 \% .{ }^{9,13}$ Oge A et al recorded the prevalence of CTS in patients with DPN as 27.8\%. ${ }^{14}$

Vogt $\mathrm{T}$ et al reported that risk of developing CTS increases in patients with additional PNP, especially in diabetics. ${ }^{15}$ They also documented that several studies showed that CTS and DPN are commonly seen together in diabetic patients. DPN is found to be a major risk factor for developing CTS. Several pathogenic mechanisms are suggested for the development of CTS in diabetics. An increased glycosylation of proteins induces structural changes of the tissues. It is hypothesized that the median nerve is made more susceptible to the pressure effects existing in the carpal tunnel when underlying DPN, a length dependent axonopathy, is present. The anatomy of the carpal tunnel may produce local vascular compromise, which is superimposed on the metabolically disordered nerve or a nerve with established endoneural ischemia, leading to frequent dysfunction in this short segment. This combination of insults may result in impaired axonal transport, producing local pathology and retrograde nerve dysfunction.

Oge A et al suggested that it will be useful to perform electrodiagnostic study in diabetic patients in whom CTS is suspected, not only at the wrist but in all four limbs to evaluate diabetic polyneuropathy. ${ }^{14}$ Perkins BA et al reported that polyneuropathy (PNP) and CTS are quite common in patients with diabetes mellitus. ${ }^{7}$ It is reported that the prevalence of CTS in patients with diabetic PNP is higher than in the general population and the risk of CTS is 2.2 times higher in diabetic women than in nondiabetic women and 2.5 times higher in diabetic than in nondiabetic men.

\section{Conclusion}

Present study concluded that, overall prevalence of diabetic neuropathy (DN) was $54.71 \%$. Prevalence of other forms viz. Polyneuropathy only, mononeuropathy only and mononeuropathy with coexistent polyneuropathy are $30.18 \%, 16.98 \%$, and $7.54 \%$ respectively. Median neuropathy at wrist was the only form of mononeuropathy observed in these cases. Severity of mononeuropathy was observed more in diabetes without polyneuropathy cases. Therefore we suggest, while evaluating a diabetic subject for polyneuropathy, palm wrist comparison test should be added to diagnose mononeuropathy at wrist also.

\section{References}

1. Committee Health Care Issues American Neurological Association: Does improved control of glycemia prevent or ameliorate diabetic neuropathy? Ann Neurol 1986;19:288-90.

2. Pirart J: Diabetes mellitus and its degenerative complications: a prospective study of 4,400 patients observed between 1947 and 1973. Diabetes Care 1978;1:168-88.

3. Young MJ, Boulton AJM, Macleod AF, Williams DRR, Sonksen PH: A multicentre study of the prevalence of diabetic peripheral neuropathy in the United Kingdom hospital clinic population. Diabetologia 19933;6:150-54.

4. Edmonds ME: The diabetic foot: pathophysiology and treatment. C! in Endocrinol Metab 1986;15:889-916.

5. Mulder DW, Lambert EH, Bastian JA: The neuropathies associated with diabetes mellitus: a clinical and 
electromyographic study of 103 unselected diabetic patients. Neurology1961;11:275-84.

6. Preston DC, Shapiro BE. Median Neuropathy at the wrist. In, Electromyography and Neuromuscular Disorders, 2nd edition. Philadelphia, Elsevier, 2005;255-80.

7. Perkins BA, Olaleye D, Bril V. Carpal Tunnel Syndrome in Patients With Diabetic Polyneuropathy. Diabetes Care 2002;25:565-9.

8. Solomon D, Katz J, Bohn R, Mogun H, Avorn J.

Nonoccupational risk factors for carpal tunnel syndrome. J Gen Intern Med 1999;14:310-4.

9. Chammas M, Bousquet P, Renard E, Poirier J, Jaffiol C, Allieu Y. Dupuytren's disease, carpal tunnel syndrome, trigger finger, and diabetes mellitus. Am J Hand Surg 1995;20:109-14.

10. Comi G, Lozza L, Galardi G, Ghilardi MF, Medaglini S, Canal N. Presence of carpal tunnel syndrome in diabetics. Effect of age, sex, diabetes duration and polyneuropathy. Acta Diabetologica 2007;22(3):259-62.

11. Stamboulis E, Vassilopoulos D, Kalfakis N. Symptomatic focal mononeuropathies in diabetic patients: increased or not? J Neurol 2005;252:448-52.

12. Thomas PK, Tomlinson DR. Diabetic and hypoglycemic neuropathy. In, Dyck PJ, Thomas PK, Griffin JW, Low PA, Poduslo JF, editors. Peripheral Neuropathy. Philadelphia:Saunders, 1993;1219-50.

13. Gamstedt A, Holm-Glad J, Ohlson C, Sundstrom M. Hand abnormalities are strongly associated with the duration of diabetes mellitus. J Intern med 1993;234:18993.

14. Oge A, Demir S, Gemalmaz A, Fikri AK. Relationship Between Carpal Tunnel Syndrome and Polyneuropathy in Diabetics: Is the Polyneuropathy A Risk Factor or Not? Turkish Journal of Endocrinology and Metabolism, 2004; 1:43-7.

15. Vogt T, Mika A, Thomke F, Hopf HC. Evaluation of carpal tunnel syndrome in patients with polyneuropathy. Muscle Nerve1997;20:153-7. 